\title{
DIAGNOSTIC CARDIAC CATHETRIZATION IN CHILDREN WITH TETRALOGY OF FALLOT: STILL RELEVANT IN DEVELOPING WORLD
}

\author{
Gul Afshan, Ahmed Usaid Qureshi, Syed Najam Haider, Tehmina Kazmi, Uzma Kazmi, Masood Sadiq \\ The Children Hospital \& Institute of Child Health, Lahore Pakistan
}

\begin{abstract}
Objective: To determine the frequency of various anatomical cardiac anomalies and variations in children with Tetralogy of Fallot diagnosed by cardiac catheterization.

Study Design: Cross sectional study.

Place and Duration of Study: Children's Hospital and Institute of Child Health Lahore, from Jan 2010 to Dec 2018.

Methodology: All children with tetralogy of fallot underwent standard cine-angiograms after obtaining written consent following basic laboratory workup.

Results: Out of 425 patients, 398 completed cardiac catheterization. The median age was 6 years (interquartile range 3.5-9 years). Confluent Branch pulmonary arteries were present in $395(99 \%)$ children. Pulmonary artery abnormalities were detected in $72(18 \%)$ patients. Two hundred and eleven (53\%) children had 283 major aortopulmonary collateral arteries with 88 having 2 or more major aortopulmonary collateral arteries. Out of all, $195(92 \%)$ had hemodynamically significant Major aortopulmonary collateral arteries (supplying $\geq 3$ lung segments) with 54 (28\%) having small (<1.33mm at origin), 105 (54\%) moderate (1.33-1.67 $\mathrm{mm}$ at origin) and $36(18 \%)$ large $(>1.67 \mathrm{~mm}$ at origin) caliber.

Conclusion: The frequencies of pulmonary artery abnormalities and various anatomic variations missed on echocardiography in the studied population were high. Diagnostic cardiac catheterization is still a relevant invasive diagnostic procedure in children with tetralogy of fallot.
\end{abstract}

Keywords: Blalock taussig, Cardiac anamolies, Left pulmonary artery, Major aortopulmonary collateral arteries, Right pulmonary artery, Tetralogy of fallot, Ventricular septal defect.

This is an Open Access article distributed under the terms of the Creative Commons Attribution License (https://creativecommons.org/licenses/by-nc/4.0/), which permits unrestricted use, distribution, and reproduction in any medium, provided the original work is properly cited.

\section{INTRODUCTION}

Tetralogy of fallot (TOF) is among the most common cyanotic congenital heart disease in children contributing to $3.5-9 \%$ of all congenital heart diseases ${ }^{1,2}$. TOF is characterized by four peculiar features i.e. large ventricular septal defect (VSD), right ventricular outflow tract (RVOT) obstruction, over riding of aorta and right ventricular hypertrophy ${ }^{3}$. The clinical features of TOF primarily depend on severity of right ventricular outflow tract (RVOT) obstruction and degree of aortic overriding. The more severe infundibular stenosis the more dramatic presentation of child with characteristic Tet spell. Optimal age for primary repair of TOF is 9-12 months of age $\mathrm{e}^{4,5}$. The paradigm management option for TOF is surgical correction with better long term outcome but a detailed pre-operative assessment of anatomical lesions and associated anamolies is required.

Diagnostic right and left heart catheterization have been an integral part of diagnostic workup for TOF up until late 1970's. With the advent for better echocardiographic assessment, the anatomic details can

Correspondence: Dr Gul Afshan, Department of Pediatric Cardiology, The Children Hospital \& Institute of Child Health, Lahore Pakistan

Received: 14 Nov 2019; revised received: 14 Jan 2020; accepted: 16 Jan 2020 accurately established through this non-invasive test in children under one year of age. Cardiac catheterization has thus become less popular due to its invasive nature and additional radiation exposure, especially in children with adequate pulmonary vasculature ${ }^{6,7}$.

Pakistan is a developing country having numerous factors including lack of education, delayed referral, poor socioeconomic status, lack of expertise and tertiary care institutions in this arena frequently result in delayed diagnosis and treatment. Chronic long-standing hypoxia and polycythemia can contribute towards re-canalization of aortopulmonary collaterals, which cannot be evaluated through echocardiography alone. Such collaterals result in potential steal phenomenon on bypass during surgery and peri-operative pulmonary haemorrhage. Diagnostic accuracy of echocardiography starts decreasing and various potentially important information cannot be provided definitely after 1 year of age.

In view of such observations, it has been hospital's institutional policy to catheterize all patients with TOF preoperatively, not only to determine the underlying anatomical variations including additional ventricular septal defects (VSDs) not delineated by echocardiography but also to occlude hemodynamically 
significant major aortopulmonary collateral arteries (MAPCAs).

The objective of this study was to evaluate the amount of additional information provided by cardiac catheterization in addition to echocardiographic findings specially Major aortopulmonary collaterals having clinical implications for operative repair and further planning in children with adequate size branch pulmonary arteries.

\section{METHODOLOGY}

This cross-sectional study was conducted at the Children's Hospital and Institute of Child Health, Lahore, from January 2010 to December 2018. All consecutive patients, 12 months of age or older with TOF diagnosed on transthoracic echocardiography were enrolled in the study. According to revised departmental protocol following observation of systemic collateral arteries complicating outcome in children with TOF, all children above 12 months of age underwent cardiac catheterization as a part of essential preoperative diagnostic workup. Significant systemic collateral arteries were defined as collaterals arising from aorta directly (type II) or indirectly (subclavian artery and tributaries, type III), with intra pulmonary type anastomosis. Such collaterals with 3 or more lung segmental supply were labelled as major aortopulmonary collateral arteries. Each major aortopulmonary collateral arteries was labelled according to Algaze et al, nomenclature describing site of origin, anastomosis type and no. of lung segments supplied (e.g. DTA-SS-3, Descending thoracic aorta- intrapulmonary segmental supply3 segments). Systemic collateral arteries type I or collaterals with hilar or extra pulmonary anastomosis were labeled as insignificant ${ }^{8}$. Patients having marked branch pulmonary hypoplasia were excluded. For standardization of peri-operative complexity, patients with Complete atrioventricular septal defect with TOF and Pulmonary atresia with VSD were also excluded. Approval was obtained from hospital's institutional review board with IERB no. 2019-44-CHICH and enrollment was commenced after gaining informed written consent from the parents. Hemodynamically stable children with room air saturation $>75 \%$ and not having any history of Tet spells were catheterized under local anesthesia. All patients were kept sedated and pain free during the procedure, using midazolam and ketamine $^{9}$. Children with history of Tet spells, room air saturation $<75 \%$ and those with hemodynamic instability were catheterized under general anesthesia. Right and left cardiac catheterizations were carried out.
Pressures and oximetry were recorded as standard recommendations ${ }^{9}$. Cine-angiograms were performed in the recommended positions ${ }^{9,10}$. Pulmonary artery sizing was done using z-scores. A vessel diameter of $<(-3)$ z-score was labeled as hypoplasia ${ }^{11}$.

Considering the frequency of TOF $(9 \%)$ confidence and confidence limits $\pm 5 \%$ sample size was calculated as 355 children with TOF at confidence level 99.9\% using Open Epi version 3. Data were analyzed using SPSS-16. The nominal variables were presented as frequencies. Median with interquartile range were calculated for ordinal and scalar variables due to nonnormally distributed data. Frequencies of associated cardiac lesions and anatomic variations were calculated. Normal distribution of each parameter was assessed using Shapiro-Wilk test. Student t-test was applied to check any significant difference between various variables with $<0.05$ considered as significant. Where the distribution was non normal Kruskal-Wallis test or Mann-Whitney test were applied ${ }^{12}$.

\section{RESULTS}

A total 425 patients underwent cardiac catheterization during this study period. Twenty seven patients not compatible with inclusion criteria after cardiac catheterization were excluded. The median age was 6 years (interquartile range 3.5-9 years) with male predominance. Median weight was $14 \mathrm{~kg}$ (interquartile range $11-20 \mathrm{~kg}$ ), median height $102 \mathrm{~cm}$ (interquartile range $90-117 \mathrm{~cm}$ ) and median surface area $0.63 \mathrm{~m}^{2}$ (interquartile range $0.52-0.81 \mathrm{~m}^{2}$ ).

All patients had levocardia (heart lying in normal left hemi thorax) except 3 patients with dextrocardia, one of whom had situs inversus as well. Frequency of anatomical lesions found in catheterized patients of TOF has shown in table-I. Thirty seven children $(9.3 \%)$ already had modified BT shunt placed for previous Tet spells or worsening hypoxemia. Most of children had single large outlet VSD with only 14 (3.5\%) having additional VSDs in mid muscular and apical region.

Confluent Branch pulmonary arteries were present in $395(99 \%)$ children with 2 having disconnected LPA and 1 having PDA continuing as RPA. Median MPA $\mathrm{z}$ scoring was -0.17 (interquartile range $-0.72 \pm$ 0.57 ), median RPA z scoring -0.17 (interquartile range $0.39 \pm 0.17$ ) and LPA median diameter -0.2 (interquartile range $-0.64 \pm 0.46$ ). Pulmonary artery abnormalities were identified in $72(18 \%)$ patients. The most common anatomical abnormality not previously documented on echo was isolated LPA origin stenosis $36(9 \%)$, followed by bilateral proximal branch pulmonary artery 
hypoplasia $18(4.5 \%)$ and isolated RPA stenosis 14 $(3.5 \%)$.

Table-I: Anatomical variations in catheterized patients of tetralogy of fallot $(n=425)$.

\begin{tabular}{l|c}
\hline Cardiac Anatomical Defects & $\mathbf{n ~ ( \% )}$ \\
\hline Confluent branch pulmonary arteries & $395(99)$ \\
\hline Isolated left pulmonary artery origin stenosis & $36(9)$ \\
\hline $\begin{array}{l}\text { Isolated right pulmonary artery origin } \\
\text { stenosis }\end{array}$ & $14(3.5)$ \\
\hline $\begin{array}{l}\text { Bilateral proximal branch hypoplasia of } \\
\text { pulmonary arteries }\end{array}$ & $18(4.5)$ \\
\hline Additional ventricular septal defects & $14(3.5)$ \\
\hline $\begin{array}{l}\text { Left anterior descending artery crossing } \\
\text { RVOT }\end{array}$ & $11(2.8)$ \\
\hline Atrial septal defects & $5(1.3)$ \\
\hline Patent ductus arteriosus & $9(2.4)$ \\
\hline Right aortic arch & $71(17.8)$ \\
\hline Major aortopulmonary collateral arteries & $283(53)$ \\
\hline Blalock Taussig Shunt & $37(9.3)$ \\
\hline
\end{tabular}

Table-II: Associated cardiac lesions found in catheterized patients of tetralogy of fallot that were missed on echocardiography $(n=425)$.

\begin{tabular}{l|c}
\hline Associated cardiac lesion & n (\%) \\
\hline Bilateral Superior vena cava & $30(7.5)$ \\
\hline $\begin{array}{l}\text { Additional muscular ventricular septal } \\
\text { defects }\end{array}$ & $14(3.5)$ \\
\hline Isolated Left Pulmonry Artery stenosis & $36(9)$ \\
\hline Coronary artery abnormalities & $11(2.8)$ \\
\hline Patent Ductus Arteriosus & $9(2.4)$ \\
\hline Right aortic arch & $71(17.8)$ \\
\hline Major aortopulmonary collateral arteries & $283(53)$ \\
\hline
\end{tabular}

Eleven children $(2.8 \%)$ had Left anterior descending (LAD) or conal branch of Right coronary artery (RCA) crossing RV outflow tract, not previously suspected on echocardiography and required surgical technique modification.

Associated lesions included atrial septal defect 5 $(1.3 \%)$ and persistent arterial duct $9(2.4 \%)$. Right sided aortic arch was present in $71(17.8 \%)$ patients while 30 $(7.5 \%)$ had bilateral SVCs. Only one patient had left SVC draining directly to LA. There was normal origin of head and neck vessels, in all patients, enrolled in our study.

Two hundred and eleven children (53\%) had 283 Major aortopulmonary collateral arteries with 88 children having 2 or more Major aortopulmonary collateral arteries as per operational definition. Origins of these Major aortopulmonary collateral arteries were mainly from descending thoracic aorta (DTA) 166 $(57 \%)$, right subclavian artery (RSCA) $54(19 \%)$, left subclavian artery (LSCA) 45 (16\%), right internal mammary artery (RIMA) 14 (5\%) and left internal mam- mary artery (LIMA) 9 (3\%). Out of these major aortopulmonary collateral arteries $54(28 \%)$ had small opening ( $<1.33 \mathrm{~mm}$ at origin), $105(54 \%)$ had moderate $(1.33-1.67 \mathrm{~mm}$ at origin) and $36(18 \%)$ had large opening ( $>1.67 \mathrm{~mm}$ at origin) from the feeding vessel. Distribution of major aortopulmonary collaterals arteries has been shown in figure.

There was no significant difference in frequency of Major aortopulmonary collateral arteries with gender $(p=0.5)$ age $(0.17)$, weight $(p=0.08)$, height $(p=0.4)$ or surface area $(p=0.95)$. There was no significant difference between frequency of Major aortopulmonary collateral arteries and associated lesions $(p=0.24)$ or BT shunt (0.5).

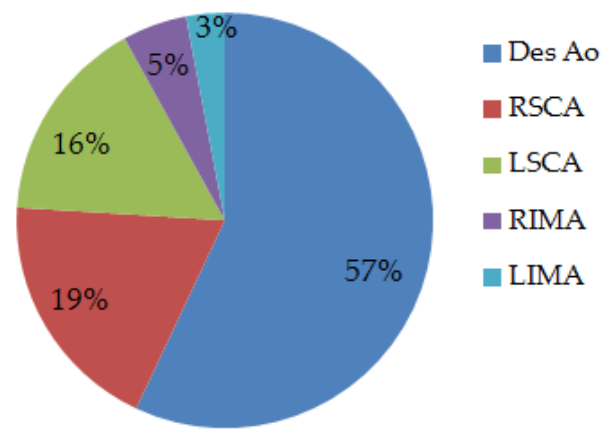

Figure: Distribution of major aortopulmonary collateral arteries (Des Ao=Descending thoracic Aorta, RSCA=Right subclavian artery, LSCA=Left subclavian artery, RIMA= Right internal mammary artery, LIMA=Left internal mammary artery).

\section{DISCUSSION}

Tetralogy of Fallot is one of the most common cyanotic congenital heart defect beyond neonatal period of life with an incidence of 0.28/1000 live births requiring surgical repair ${ }^{13}$. Cine-angiogram has been the gold standard for pulmonary vasculature evaluation prior to surgery ${ }^{14}$. Magnetic resonance angiography has been used but frequently requires anaesthesia in small children and doesn't allow intervention ${ }^{15,16}$. In developed world, the diagnosis of TOF is frequently made prenatally ${ }^{17}$. However, in developing countries like Pakistan there are many social factors in addition to lack of expertise.

In our study, majority of patients were relatively older between 5-15 years of age due to less efficient primary and secondary healthcare structure. TOF has equal gender distribution, though in our study, there was a male predominance $(2.1: 1)^{18}$. This finding was more of a social norm rather than a true statistical diff- 
erence as previously documented in various local studies ${ }^{19}$.

The overall incidence of pulmonary artery abnormalities in our population was found to be $18 \%$, which was comparable to the data reported by Sharma et al20. Bacha et al, also observed pulmonary artery abnormalities in $20 \%$ cases $^{21}$. The incidence recorded in various other studies have been as high as up to $39 \%$, though unlike our study, they had included all forms of TOF and hence cannot be standardized ${ }^{22}$. Isolated LPA stenosis was identified in $9 \%$ of this study cases. This finding was equal to the reported occurrence of $3 \%$ and 10\% from Asia and Europe respectively ${ }^{22,23}$. RPA stenosis $(3.5 \%)$ was also comparable with data by Farsani, where it was found to be $2.2 \%^{22,23}$. A local study conducted at National Institute of Cardiovascular Diseases (NICVD) Karachi, showed 5 out of 31 patients $(16 \%)$ with TOF had markedly hypoplastic pulmonary arteries $^{7}$.

In majority of patients with TOF, there is single malaligned subaortic VSD but some patients have additional muscular VSDs. Additional muscular VSDs were present in $3.5 \%$ of patients. This is again comparable to other workers study ${ }^{11}$.

There is no functional importance of right sided aortic arch but its presence signifies to paediatric cardiologists to further investigations in Tetralogy of Fallot patients. Right aortic arch was present in $17.8 \%$ patients similar to previously reported incidence of $20-25 \%$ cases $^{24}$. It was also comparable to study conducted locally in Pakistan ${ }^{22}$.

PDA was detected in $2.4 \%$ cases same as recorded by studies by other workers 22 . This relatively low incidence of PDA can be may be related to late presentation of these patients that lead to spontaneous duct closure.

Bilateral superior vena cava (SVC) was present in $7 \%$ patients. It is an important finding for the cannulation before cardiopulmonary bypass and has been reported to be as high as $11 \% 25$.

The incidence and distribution of Major aortopulmonary collateral arteries were independent of disease severity or morphological variations. The incidence of high percentage in our study was probably due to late presentation and chronic long standing hypoxemia. Major aortopulmonary collateral arteries have significant clinical implications pre and post-operatively and can lead to development of a various complications like massive hemoptysis because of erosion of bronc- hial vessels due to gross enlargement development of very fatal pulmonary edema postoperatively if not embolized ${ }^{27}$.

Coronary arteries abnormalities have significant impact to adopt specific surgical technique in patients with TOF as it reduces risk of surgical repair. In this study, coronary artery abnormality was present in $2.8 \%$ patients. This finding is consistent with other studies $^{14}$.

\section{LIMITATION OF STUDY}

We did not study the clinical peri-operative outcome of these children. In view of the high frequency of major aortopulmonary collateral arteries in even children with "optimal" morphology, a comprehensive prospective study is required to pinpoint and further elaborate the significance of such collaterals.

\section{ACKNOWLEDGEMENT}

The authors of this article thank all participating physicians for providing editorial support,statistical analysis and are specially indebted to all those families who permitted the hearts of their children to be included in the archive and help us to provide detailed information regarding study.

\section{CONCLUSION}

The frequencies of pulmonary artery abnormalities and various anatomic variations in the studied population were high. Major aortopulmonary collateral arteries were frequent in our population even with adequate size branch pulmonary arteries. These frequency size and distribution of MAPCAs were independent of age, surface area, and degree of cyanosis or underlying pulmonary vasculature anatomy. Diagnostic cardiac catheterization is still a unique and relevant invasive procedure in children with TOF to delineate and possibly occlude such channels to avoid perioperative complications.

\section{CONFLICT OF INTEREST}

This study has no conflict of interest to be declared by any author.

\section{REFERENCES}

1. Fyler DC, Buckley LP, Hellenbrand WE. Infant heart disease, congenital heart disease, New England Regional Program. Pediat 1998; 102(1 Pt 2): 258-59.

2. Sadiq M, Roshan B, Khan A, Latif F, Bashir I, Sheikh SA. Pattern of pediatric Heart Disease in Pakistan. J Coll Physicians Surg Pak 2002; 12(1): 149-53.

3. Shinebourne EA, Anderson RH. Fallot's tetralogy. In: Anderson RH, Baker EJ, McCartney RFJ, Rigby ML, Shine Bourne EA, Tynan M, (Ed). paediatric cardiology. $2^{\text {nd }}$ ed. Edinburgh: Churchill Livingstone; 2002:p.1213-50. 
4. Steve Daviss. Tetralogy of Fallot with and without pulmonary atresia. In: Ninstitute of child healtholas DG, Ungerleider RM, Spevak PJ, Greeley WJ Cameron DE, Lappe DG, et al, (edi). Critical heart disease in infants and children. $2^{\text {nd }}$ ed. St. Louis; Mosby, 2006: p.755-65.

5. Siwik ES, Erenberg F, Zahka KG. Tetralogy of Fallot. In: Allen HD, Shaddy RE, Driscoll DJ, Feltes TF, editors. Moss and Adams heart diseases in infants, children and adolescents including the fetus and young adult. 7th ed.Philadelphi Lippincott William \& Wilkins, 2008:p.888-910.

6. Holmqvist C, Hochbergs P, Bjorkhem G, Brockstedt S, Laurin S. Pre-operative evaluation with MR in tetralogy of fallot and pulmonary atresia with ventricular septal defect. Acta Radiol 2001; 42(1): 63-69.

7. Aziz KU, Tetralogy of Fallot. In: Aziz KU, (Ed). Heart diseases in children. $2^{\text {nd }}$ ed. Karachi; 2000:p.107-28.

8. Algaze CA, Penglf, Feinstein JA, Reddy MV, Frank LH, Perry SB. Major aortopulmonary collateral artery nomenclature. J Am Coll Cardiol 2013; 61(10): 543-48.

9. Grifka RG. Cardiac catheterization and angiography. In: Allen HD, Shaddy RE, Driscoll DJ, Feltes TF, (Ed). Moss and Adams heart diseases in infants, children and adolescents including the fetus and young adult. 7th ed. Philadelphia: Lippincott William \& Wilkins; 2008: p208-37.

10. Fellows KE. Angiography of congenital heart disease. In: Lock JE, Keane JF, Fellows KE, (Ed). Diagnostic and interventional catheterization in congenital heart disease. Boston: Martinus Nijhoff 1987:p;63-90.

11. Ventricular septal defect with pulmonary stenosis or atresia. In: Kouchoukos NT, Blackstone EH, Hanley FL, Doty DB, Karp RB,(Ed). Kerklin/Barratt-Boyes. Cardiac surgery. Morphology, diagnostic criteria, natural history, techniques, results, and indications. $3^{\text {rd }}$ ed. Philadelphia: Churchill Livingstone; 2003:p;948-94.

12. Razali N, Wah YB. power comparisons of Shapiro-wilk, Kolmogorov-Smirnov, Lilliefors and Anderson-Darling tests. J Stat Mod 2011; 2(1): 21-33.

13. Apitz C, Webb GD, Redington AN. Tetralogy of fallot. Lancet 2009; 374(4699): 1462-71.
14. Bernardes RJ, Marchiori E, Bernardes PM, Monzo Gonzaga MB, Simoes LC. A comparison of magnetic resonance angiography with conventional angiography in the diagnosis of Tetralogy of Fallot. Cardiol Young 2006; 16(3): 281-88.

15. Siripornpitak S, Pornkul R, Khowsathit P, Layangool T, Promphan W, Pongpan institute of child health B Cardiac CT angiography in children with congenital heart disease. Eur J Radiol 2013: 82(7): 1067-82.

16. Garg N, Walia R, Neyaz Z, Kumar S. Computed tomographic versus catheterization angiography in Tetralogy of Fallot. Asian Cardivasc Thorac Ann 2015; 23(2): 164-75.

17. Wang XM, Wu LB, Sun C, Liu C, Chao BT, Han B, et al. Clinical application of 64-slice spiral CT in the diagnosis of the Tetralogy of Fallot. Eur J Radiol 2007; 64(2): 296-301.

18. Bailliard F, Anderson RH. Tetralogy of Fallot. Orphanet J Rare Dis 2009; 4(2): 1-5.

19. Saeed S, Hyder SN, Sadiq M. Anatomical variations of pulmonary artery and associated cardiac defects in tetralogy of fallot. J Coll Phys Surg Pak 2009; 19(4): 211-14.

20. Sharma SN, Sharma S, Shrivastava S, Rajani M, Tandon R. Pulmonary arterial anatomy in Tetralogy of Fallot. Int J Cardiol 1989; 25(1): 33-37.

21. Bacha EA, Kreutzer J. Comprehensive management of branch pulmonary artery stenosis. J Interv Cardiol 2001; 14(3): 367-76.

22. Sheikh AM, KazmI U, Syed NH. Variations of pulmonary arteries and other associated defects in tetralogy of fallot. Springer Plus 2014; 3(1): 467-70.

23. Farsani HY. Determination of tetralogy of fallot characteristics in iranian patients. Iran J Pediatr 2007; 17(1): 5-10.

24. Elzenga NJ, von Sylen RJ, Frohn-Mulder I, Essed CE, Bos E, Quaegebeur JM. Juxtaductal pulmonary artery coarctation: an underestimated cause of branch pulmonary artery stenosis in patients with pulmonary atresia or stenosis and a ventricular septal defect. J Thorac Cardiovasc Surg 1990; 100(3): 416-24.

25. Chowdhury UK, Kothari SS. Anomalous origin of the right coronary artery from the left anterior interventricular coronary artery in the setting of tetralogy of fallot. Cardiol Young 2006; 16(5): 501-503. 